\title{
INTERSTÍCIOS URBANOS
}

\author{
Pétilin Assis de Souza, Arlete Maria Francisco
}

Universidade Estadual Paulista "Julio de Mesquita Filho" - UNESP. Curso de Arquitetura e Urbanismo, Presidente Prudente - SP. E-mail: petilindesouza@gmail.com

\begin{abstract}
RESUMO
Presidente Prudente passou por um processo de expansão territorial que resultou na configuração de vazios urbanos variados. Entender estes vazios como sendo caracterizados apenas por grandes áreas é ignorar o desenho urbano em pequena escala, ou seja, no nível do lote, da rua e do bairro. Dar atenção a esses pequenos espaços residuais, como vielas, sobras de esquina, miolos de quadras, quintais subutilizados, denominados por Christopher Alexander (1977) de "interstícios urbanos", torna-se necessário, a fim de possibilitar a elaboração do redesenho urbano de determinada área da cidade. Este trabalho analisa uma área na Zona Leste da cidade de Presidente Prudente, define diretrizes de intervenção urbana, propõe uma intervenção projetual em uma área menor dentro da área analisada, partindo do redesenho viário. Transformando, assim, espaços intersticiais em espaços com qualidades arquitetônicas, urbanísticas e ambientais, coletivizandoos, independente de sua escala de abrangência, e reintegrando-os ao desenho da malha urbana em menor escala.
\end{abstract}

Palavras-chave: desenho urbano, interstícios urbanos, Presidente Prudente

\section{URBAN INTERSTICES}

\begin{abstract}
The territorial expansion process in Presidente Prudente resulted in the setting of various urban empty spaces. Understanding these empty spaces as just large areas is disregarding the small-scale urban design, in other words, in the lot, street and neighborhood levels. Paying attention on these small residual spaces as alleys, leftover corner, block centers, underutilized backyards, named by Christopher Alexander (1977) as "urban interstices", becomes necessary to enable the urban redesign of a particular area of the city. This paper examines an area in the East Zone of the city of Presidente Prudente, sets guidelines for urban intervention, proposes a projectual intervention in a smaller area within the analyzed area, starting with the road redesign. Thus, transforming interstitial spaces into spaces with architectural, urban and environmental qualities, collectivizing them, regardless of their range of coverage, and reintegrating them into the design of the urban complex in a smaller scale.
\end{abstract}

Keywords: urban design, urban interstices, Presidente Prudente 


\section{INTRODUÇÃO}

A proposta deste trabalho contempla o estudo de pequenos vazios nos miolos dos quarteirões e sobras de esquinas - denominados interstícios urbanos - de uma área consolidada de Presidente Prudente, a Zona Leste. Estes interstícios surgem devido ao desenho urbano não contemplar um melhor aproveitamento destas pequenas áreas no momento de implantação dos loteamentos. Tal estudo possibilitará a elaboração da proposta do redesenho urbano da área de intervenção.

O trabalho propõe uma intervenção embasada na teoria do espaço externo positivo proposta por Christopher Alexander (1977), a fim de preencher estes espaços intersticiais e tornando possível seu uso. Esta intervenção se faz no nível do planejamento local, uma vez que se propõe a coletivização dos quintais subutilizados. Parte-se, então, da negociação, onde a contrapartida para doação desses espaços é a requalificação dos mesmos. Ou seja, transformar-seão espaços negativos em espaços positivos, ocupando-os de maneira a dar maior continuidade ao espaço intersticial e agora público, tratando as áreas vazias e propondo uma rede viária a favor do pedestre.

Entende-se, portanto, que é necessário criar a identificação do morador com a cidade, transformar pequenos espaços residuais individuais em espaços projetados coletivos, tornando os diversos usuários do espaço em responsáveis pelo mesmo, valorizando, assim, a área da habitação e seu entorno imediato. Hertzberger (1999, p.28) defende essa ideia quando afirma: "Se você não tem um lugar que possa chamar de seu, você não sabe onde está".

\section{EMBASAMENTO TEÓRICO}

\section{Interstícios urbanos}

A definição de interstício urbano é feita por Guerreiro (2008), em que a autora faz a relação de interstício em biologia, quando se refere à pequena área, orifício ou espaço existente na estrutura de um órgão ou tecido orgânico. 

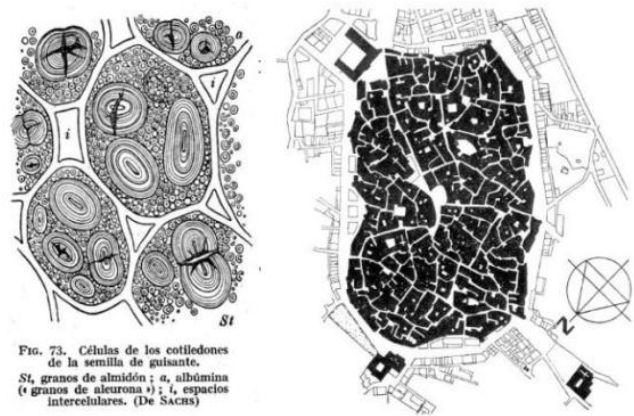

Figura 1. À esquerda, arranjo celular da semente de ervilha, com os respectivos espaços intersticiais, em branco. À direita, morfologia urbana de uma cidade orgânica, com os edifícios em preto (positivo) e os espaços intersticiais em branco (negativo).

(Fonte: GUERREIRO, 2008, p. 3).

Faz-se a analogia de que na arquitetura o conceito de interstício é usado para designar o espaço não edificado resultante da disposição e agregação dos edifícios. Em termos arquitetônicos o interstício é o vazio, contrapondo-se ao espaço edificado, denominado cheio (Fig.1).

Guerreiro (2008) entende que essas designações por si só denunciam a importância do edifício enquanto objeto de desenho, e aponta:

Tal fato tem levado a atribuição de menor importância ao espaço intersticial resultante da organização dos edifícios, ou seja, ao espaço público, aquele que coletivamente mais valorizamos na cidade.

Assim, e para além dos fatores habitualmente enunciados para explicar o estado caótico das nossas cidades, especulação imobiliária, pobreza, acessibilidade, etc., verificamos que existe também uma crise de percepção do espaço intersticial enquanto forma, ou seja, enquanto objeto de planeamento e de desenho. (GUERREIRO, 2008, p. 3).

\section{Os interstícios urbanos como espaço externo positivo}

O autor Christopher Alexander (1977) em sua teoria oferece uma linguagem de padrões para arquitetura e planejamento. Ele divide suas análises em Cidades, Arquitetura e Construção. Aqui serão estudados os níveis de Cidades e de Arquitetura. Sendo que o ponto focal da discussão se situa no campo da Arquitetura, acerca do Espaço Externo Positivo. Os padrões discutidos servirão como diretrizes projetuais para intervenção na área definida.

Para Alexander (1977), as pessoas precisam fazer parte de uma unidade espacial identificável. É necessário definir os bairros nos quais as pessoas vivem, limitando-os no máximo a 300 metros de diâmetro, e a 400 ou 500 habitantes. Dentro deste bairro identificável, é necessário distribuir o agrupamento de moradias de maneira a configurar conjuntos bastante informais, porém igualmente identificáveis, de 8 a 12 unidades, em torno de vias e áreas externas de uso comum, distribuindo os grupos de moradias de maneira que qualquer pessoa possa passar por 
entre elas sem se sentir uma invasora.

Tais áreas, ou espaços externos, podem ser negativos ou positivos. Um espaço é negativo quando os edifícios estão colocados de tal modo que o espaço resultante é apenas residual. Um espaço exterior é positivo quando tem uma forma distinta e coerente tão importante como as formas dos edifícios que o rodeiam. Espaços negativos são amorfos, enquanto que em espaços positivos é possível fazer a inversão da figura-fundo de forma a caracterizar uma figura equilibrada.

Em suma, Alexander (1977) discute os inúmeros padrões que podem aproximar a vivência com a cidade para uma escala mais humana. Revivendo a rua, os espaços de encontro, o contato social, atualmente tão abandonados por diversos fatores. Mais do que projetar para o indivíduo, o autor entende a importância deste e o insere no espaço coletivo como parte integrante de um todo, repensando o modelo atual de cidade que tanto desconsidera seus usuários.

\section{A ZONA LESTE DE PRESIDENTE PRUDENTE}

Presidente Prudente desenvolveu-se inicialmente no eixo da ferrovia Alta Sorocabana, principalmente por sua importância para o escoamento da produção econômica e local, originando-se da Vila Goulart, porção oeste da via férrea. Maria Encarnação Beltrão Sposito (1983) ressalta que foi principalmente para oeste que a cidade mais cresceu durante a década de 1970 e início da de 1980. Além de a Zona Leste contar com uma topografia bastante acentuada, o que torna a área menos favorável à ocupação - mesmo sendo a topografia um fator facilmente minimizado -, o baixo nível de acessibilidade aos bairros contribuiu para sua exclusão.

As diferenças entre as áreas que se dividem pela ferrovia, a zona oeste e a zona leste (onde foi possível constatar a alta incidência de vazios), acentuaram-se gradativamente com o desenvolvimento da cidade. A esse respeito Sposito (1983) pontua que:

(...) para os habitantes do meio urbano, estradas de ferro, de rodagem ou mesmo rios constituem-se além de barreiras geográficas, devido as dificuldades causadas para a circulação de automóveis e pessoas, também em falsas barreiras psicológicas. É comum ouvir-se falar das áreas localizadas além dos obstáculos, como "do lado de lá do rio", "do outro lado da linha", "depois da estrada", etc. Todas essas são expressões que encerram para sua área um caráter de não muito boas para o desenvolvimento de atividades comerciais e de serviços, ou para habitação. (SPOSITO, 1983, p. 83). 


\section{ÁREA DE ESTUDO}

\section{Levantamentos e análise}

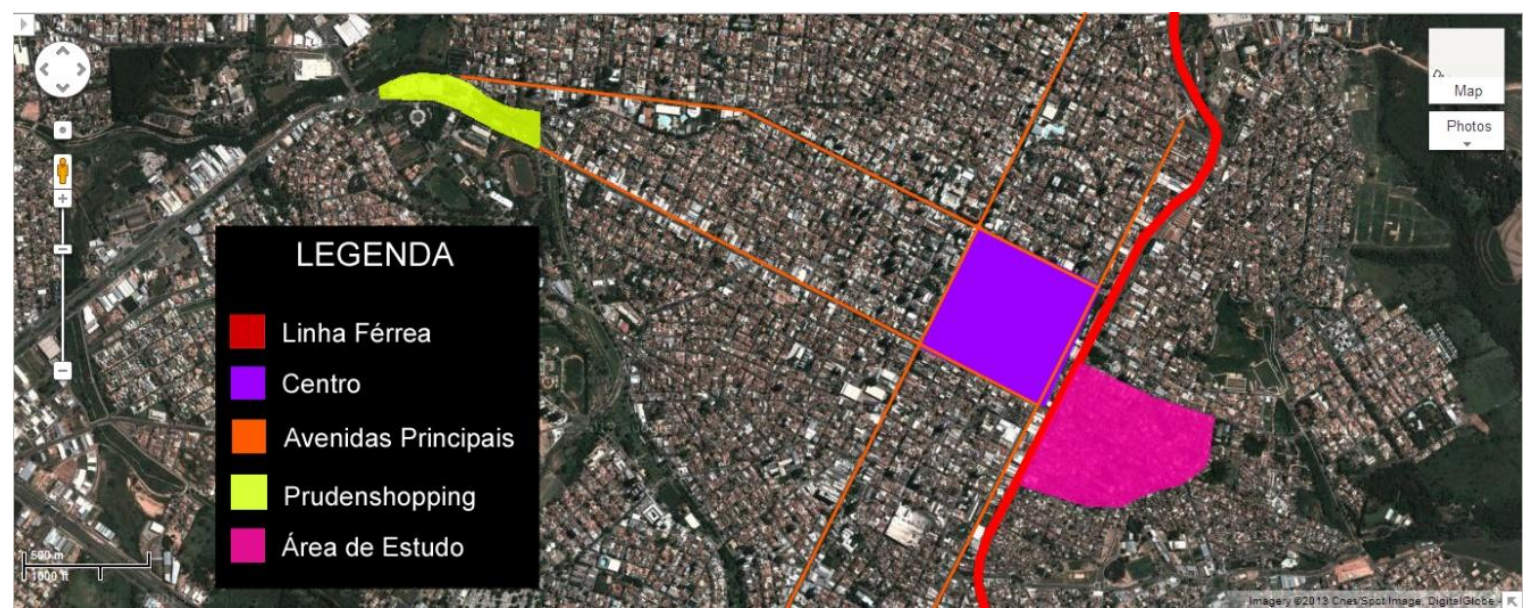

Figura 2. Localização da área de estudo

(Fonte: Google Maps 2013 - Modificado pela autora)

Analisando a Zona Leste da cidade de Presidente Prudente em sua totalidade, delimitou-se a área de estudo destaca na figura 2.

A delimitação da área de estudo deu-se pela grande incidência de interstícios urbanos fator primordial que gera a presente discussão - que se torna clara quando se realiza o exercício de inversão da figura-fundo, resultando nas seguintes figuras (Fig. 3A e 3B):

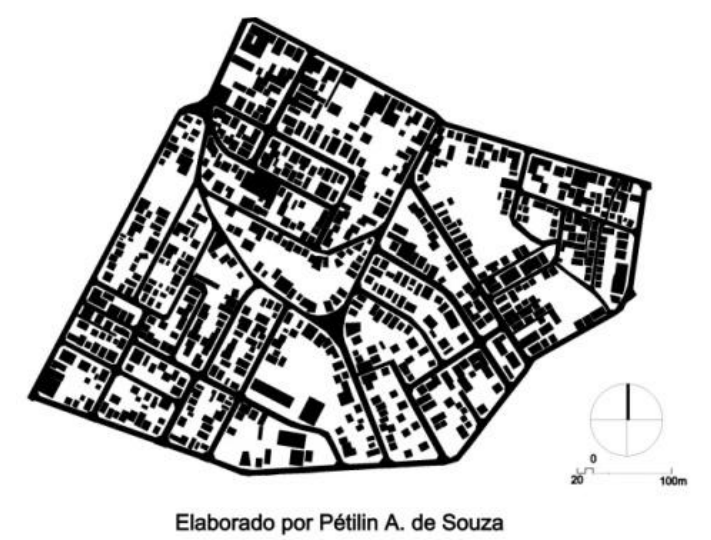

Figura 3 A. Inversão da figura-fundo

(Elaborado pela autora). 


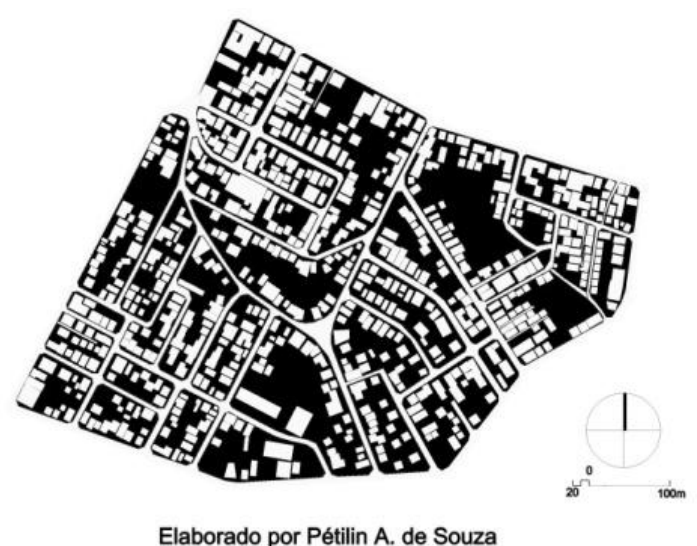

Figura 3 B. Inversão da figura-fundo (Elaborado pela autora).

Como discutido ao longo do trabalho, essas imagens (Fig. 3A e 3B) caracterizam uma figurafundo visualmente sem equilíbrio, ou seja, as áreas vazias tem maior destaque e são amorfas, configurando-se, então, como espaços externos negativos. Assim, a intenção é que estes vazios sejam analisados pautados na teoria apresentada, para que então seja possível a elaboração da proposta projetual para os mesmos.

Para esta área, serão propostas diretrizes de intervenção, e dentro desta delimitou-se áreas menores, uma vez que o estudo teórico orienta de maneira a definir os bairros, limitando-os a 300 metros de diâmetro, e a 400 ou 500 habitantes. Dividiu-se, assim, a área em cinco áreas menores, levando em consideração o diâmetro proposto e que está representado nos eixos A e B da Figura 4.

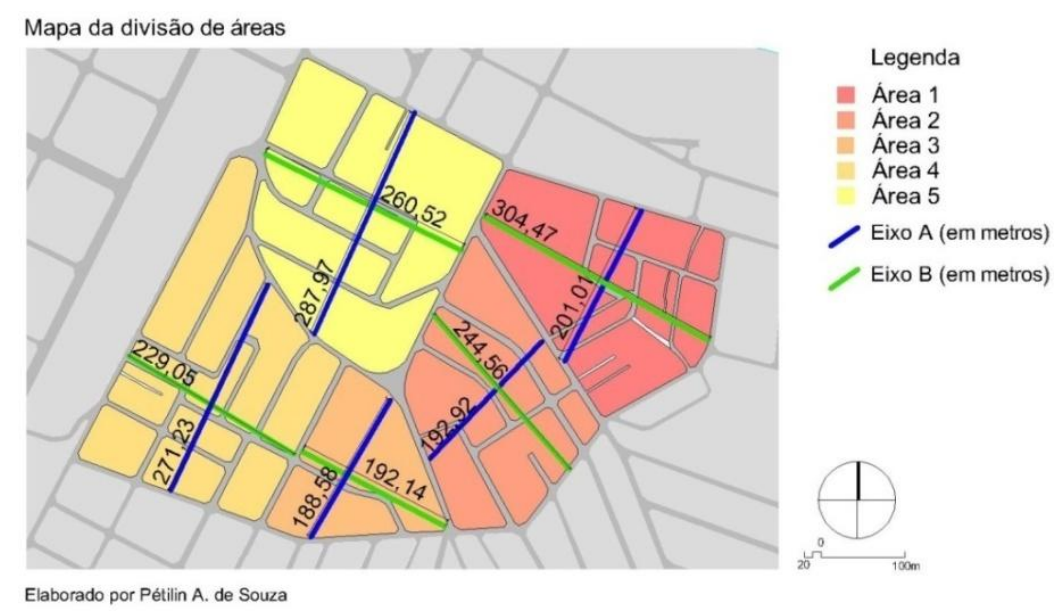

Figura 4. Divisão de áreas

(Elaborado pela autora)

\section{METODOLOGIA}

A metodologia de trabalho abarca a área de estudo em suas divisões, e consistem na proposta de melhorias do sistema viário para garantir uma melhor circulação, tornando o pedestre 
o protagonista do meio urbano, garantindo, assim, acessibilidade pedonal às áreas de intervenção e seus interstícios.

Aumentar-se-ão quantitativamente, portanto, as vias pedonais em comparação às vias urbanas, fazendo o tratamento adequado das mesmas, que consiste na repaginação do piso, implantação de áreas de convívio e arborização adequada a fim de melhorar o conforto dos moradores e transeuntes, bem como de iluminação compatível, para garantir a segurança e o uso noturno.

Dentro dessas áreas menores propõe-se a interação das moradias em agrupamentos de até 12 casas - considera-se este número como forma de gerar identificação dos moradores com uma área de menor abrangência, segundo Alexander (1977) - e a implantação de áreas livres comuns entre as moradias, como em pequenas vilas, configurando áreas de intervalo - assim como foi realizado com uma das áreas apresentada a seguir.

O intervalo é entendido por Hertzberger (1999, p 32) como "o encontro e reconciliação entre a rua, de um lado, e o domínio privado, de outro". É o espaço que pertence tanto à rua, quanto à casa, "um lugar em que os dois mundos se superpõem em vez de estarem rigidamente demarcados" (HERTZBERGER, 1999, p. 32).

Do agrupamento de moradias, entendem-se os quintais subutilizados como áreas com potencial para coletivização e tratamento ao nível da área dividida. A partir disso, é necessário propor percursos que conectem a área como um todo, com espaços de permanência e contemplação tratados paisagisticamente, utilizando os fundos dos lotes para áreas coletivas.

Esta é uma intervenção no nível do planejamento local, dada à intenção de coletivização dos quintais subutilizados. Tem-se a proposta de negociação, que dá como contrapartida para doação desses espaços, a requalificação dos mesmos. A diretriz não é privar o morador de seu quintal por inteiro, mas dividi-lo em três partes: área privada, área de intervalo e área pública, estas duas últimas sim sendo coletivas.

A figura 5 mostra um exemplo sem escala de como isto se daria em quatro lotes da área de intervenção. Sendo que a área de intervalo não está necessariamente presente em todos os lotes, mas buscou-se torná-la acessível através das áreas privadas. 


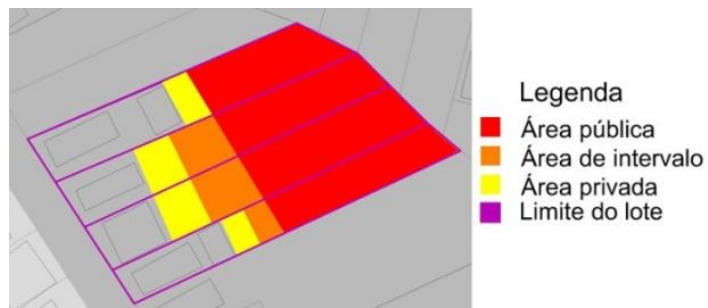

Figura 5. Exemplo de coletivização de quintais subutilizados.

(Elaborado pela autora - Sem escala)

\section{RESULTADO}

A figura 6 mostra o resultado do processo projetual na área 1 da figura 4 . A área de intervalo não está necessariamente presente em todos os lotes, mas buscou-se torna-la acessível através das áreas privadas.

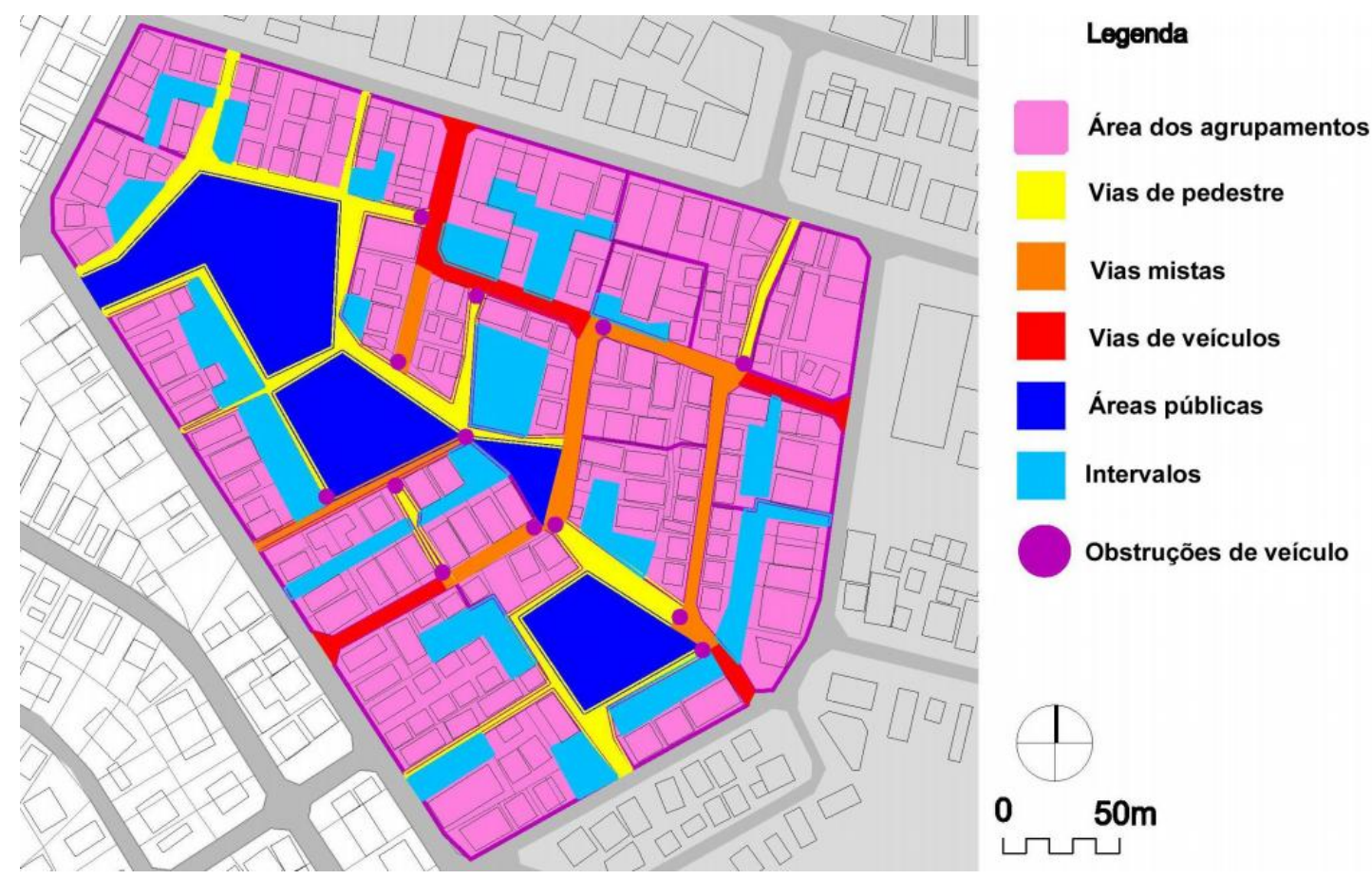

Figura 6. Plano Geral das Áreas de Intervenção (Elaborado pela autora)

Neste projeto a premissa é que o morador doa parte de seu quintal, uma vez que se entende o mesmo como sendo subutilizado, o Poder Público executa a obra, contudo, é o próprio morador que mantém a área de intervalo, uma vez que este se configura por ser uma área privada de uso coletivo do agrupamento. Já a área pública é de responsabilidade do Poder Público, por ser totalmente aberta.

Este projeto apresenta um programa aberto, ou seja, há a imprevisibilidade de usos. Hertzberger (1999, p. 94) entende este processo projetual como a definição de "uma forma ampla que, mudando pouco ou nada, é adequada para acomodar situações diferentes porque oferece 
continuamente novas oportunidades para novos usos".

Assim, para o autor, o projeto deve conceber a forma de maneira que esta se torne interpretável por sua capacidade de acomodação, que permita ser preenchida por associações e conduza a uma dependência mútua com os usuários, dando suporte potencial de significado, criando, assim, a identidade com o espaço.

\section{CONSIDERAÇÕES FINAIS}

Neste trabalho, buscou-se dar atenção aos pequenos vazios encontrados na malha urbana, entender sua formação, complexidade e possíveis formas de ocupá-los, a fim de reintegrá-los ao desenho urbano como espaços externos positivos.

Percebeu-se que lotes delgados acabam tendo seus quintais subutilizados, seja por suas dimensões, seja pela topografia do local. Assim, espaços remanescentes tomam conta de áreas em que ocorreram loteamentos que não atentaram para configuração desses espaços intersticiais.

A imprevisibilidade de usos a que este estudo se dispôs a entender, que se reflete no desenho do intervalo e deixa livre para intervenção por parte de seus usuários é o que tornará possível a identificação do morador com o ambiente próximo construído. Assim, o sentido de pertencimento ao local se torna mais real e verdadeiro. O usuário, morador e pedestre, independente de sua denominação, precisa entender seu lugar na cidade, e saber que ele existe.

\section{REFERÊNCIAS}

ALEXANDER, C. Uma Linguagem de Padrões. Porto Alegre: Bookman, 2013. (Original publicado em 1977).

GUERREIRO, M. R., Interstícios urbanos e o conceito de espaço exterior positivo. Forum Sociológico [Online], 18 | 2008. Disponível em <http://sociologico.revues.org/218> Posto online em 19 Julho 2012, acesso em 27 Março 2013.

HERTZBERGER, H. Lições de Arquitetura. São Paulo: Martins Fontes, 1999.

2000.

PRESIDENTE PRUDENTE. Lei complementar 153, de 10 de Janeiro de 2008. Dispõe sobre a Lei de Zoneamento do Uso e Ocupação do Solo, da Área Urbana do Município de Presidente Prudente e dá outras providenciais. Presidente Prudente, 2008.

SPOSITO, M. E. B. O chão em Presidente Prudente: A lógica da expansão territorial urbana. Dissertação de Mestrado - UNESP Instituto de Geociências e Ciências Exatas de Rio Claro. Rio Claro, 1983. 